\title{
Liquid Absorbance Standards
}

\author{
R. W. Burke, E. R. Deardorff, and O. Menis \\ Institute for Materials Research, National Bureau of Standards, Washington, D.C. 20234
}

(June 14, 1972)

\begin{abstract}
Errors in the measurement of the absorbances of liquid filters result from instrumental and chemical uncertainties. This paper presents a systematic study of these variables on the absorbances of selected filters. Three types of liquid filters are discussed. These are (1) individual solutions of high purity compounds, (2) composite mixtures and (3) aqueous solutions of organic dyes. The accuracy of the absorptivity data is established using NBS-calibrated glass filters. The magnitude of the errors arising from spectral bandpass, beam geometry, stray light, internal multiple reflections, and refractive index are delineated. Finally, as a practical outgrowth of this study, the development and issuance of NBS Standard Reference Material 931, Liquid Absorbance Standards for Ultraviolet and Visible Spectrophotometry, is described.
\end{abstract}

Key words: Absorptivity data; accuracy; liquid absorbance standards; Standard Reference Materials.

\section{Introduction}

In the use of filters for checking the accuracy of the photometric scale of spectrophotometers, one needs materials which exhibit absolute spectral neutrality. Such ideal filters are not available at present. The use of the materials which have been suggested is limited by instrumental and sample variables. For this reason, one must carefully specify conditions which define the other sources of errors.

The first part of this paper reviews several of the more important instrumental parameters and discusses their effects on absorbance measurements. Examples from the literature are given to illustrate the magnitude of the errors arising from spectral bandpass, stray light, nonparallel radiation, and multiple reflections. The second part presents some experimental studies of several materials which may serve as calibration "filters" or standards.

\section{Instrumental Parameters}

\section{A. Wavelength Accuracy}

The absorbances of most samples are sufficiently wavelength dependent that even in the most favorable regions of maxima and minima a wavelength error of 1-2 nm can produce absorbance errors of a few tenths of a percent. When performing measurements on the slopes of absorption peaks, the wavelength setting is obviously much more critical and errors are typically several percent per nanometer. Wavelength accuracy, therefore, becomes especially important when making absorbance measurements at, for example, an isosbestic point.
A line source provides the most definitive means for establishing the accuracy of the wavelength scale. The best single source is a mercury lamp which may be used throughout the range of $200-1000 \mathrm{~nm}$. For calibration in the visible region, helium lines are also useful.

Gibson $[1]^{1}$ has discussed the use of mercury and helium sources and has listed those lines best suited for wavelength calibration. Other sources which have been used include neon, cadmium, cesium, and sodium. The M.I.T. Wavelength Tables [2] summarizes the most prominent emission lines of these elements. Not all wavelengths are given and care must be taken in using any of these lines in order not to confuse closely adjacent lines with the one being checked. For those spectrophotometers having a hydrogen or deuterium source, the emission lines at 486.13 and $656.28 \mathrm{~nm}$ (H) or 485.99 and $656.10 \mathrm{~nm}$ (D) may provide convenient checks at these wavelengths.

Cialibrated holmium oxide and didymium glasses may be useful secondary standards, particularly for checking recording spectrophotometers in which a dynamic check of the instrument is often desirable. The apparent absorption maxima of these filters, however, may vary with spectral bandpass. Therefore, for the highest accuracy, they should be calibrated for the spectral bandpass at which they are to be used.

In general, prism instruments require more frequent calibration than the grating type because their dispersion is temperature dependent. Corrections in the visible region are of the order of $0.1 \mathrm{~nm}$ per degree Celsius. Hysteresis effects must also be considered

\footnotetext{
${ }^{1}$ Figures in brackets indicate the literature references at the end of this paper.
} 
and the wavelength settings should always be approached from the same direction.

\section{B. Finite Bandwidth}

Spectral bandpass differences undoubtedly account for a significant portion of the discrepancies in molar absorptivity values reported in the literature. Some have resulted from the employment of inadequate instrumentation; others have resulted from improper use of these instruments or complications arising from solution equilibria.

Increasing the spectral bandpass at an absorption maximum has two effects on apparent peak heights: (1) the observed values are always less than the true values and (2) the differences between the two are proportionally greater at higher absorbances. Thus, for a finite bandpass, a plot of absorbance versus concentration or path length will always have a smaller slope than it does in monochromatic radiation and, in addition, will be concave to the concentration axis. Figure 1 illustrates these effects. The reverse behavior will be observed for measurements at an absorption minimum. Meehan [3] has given a simple example which verifies these two effects mathematically.

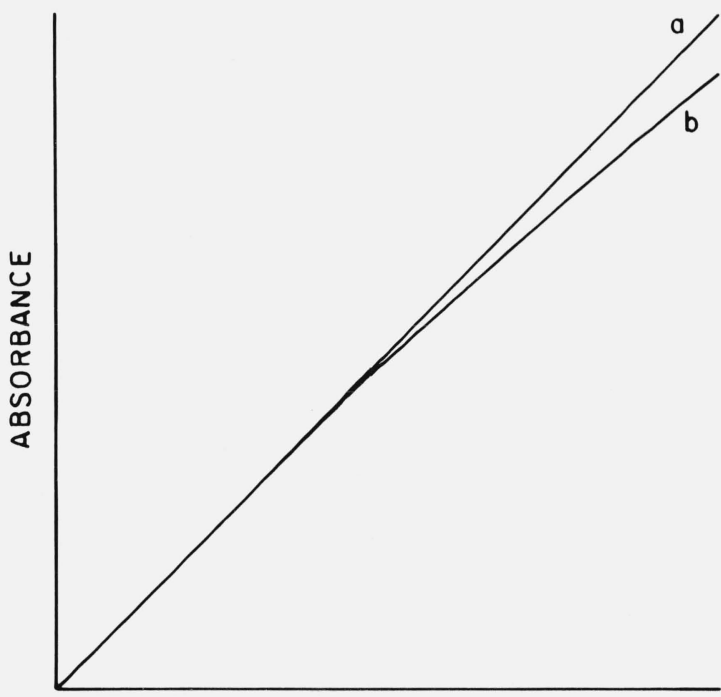

CONCENTRATION (PATH LENGTH)

FigurE 1. Effect of spectral bandpass on absorbance: (a) Monochromatic radiation (b) Finite bandwidth.

Consider that an absorbing system is illuminated by two monochromatic radiations of wavelengths $\lambda_{1}$ and $\lambda_{2}$ and that the Lambert-Beer law is obeyed at each wavelength with absorptivities $a_{1}$ and $a_{2}$. If the effective intensities of the two wavelengths are $I_{1}$ and $I_{2}$, respectively, the transmittance, $T$, is

$$
T=\left(I_{1} \cdot 10^{-a_{1} b c}+I_{2} \cdot 10^{-a_{2} b c}\right) /\left(I_{1}+I_{2}\right)
$$

where $b=$ path length and $c=$ concentration. If $\lambda_{1}$ is the wavelength of maximum absorption so that $a_{1}>a_{2}$, then

$$
T=\frac{1}{(1+r)} \cdot 10^{-a_{1} b c}\left[1+r \cdot 10^{\left(a_{1}-a_{2}\right) b c}\right]
$$

where $r=I_{2} / I_{1}$. The absorbance, $A$, defined as $-\log$ $T$ is

$$
A=a_{1} b c+\log (1+r)-\log \left[1+r \cdot 10^{\left(a_{1}-a_{2}\right) b c}\right]
$$

which may be differentiated with respect to $b c$ to give

$$
\begin{array}{r}
d A / d(b c)=a_{1}-\left[r\left(a_{1}-a_{2}\right) 10^{\left(a_{1}-a_{2}\right) b c}\right] / \\
{\left[1+r \cdot 10^{\left(a_{1}-a_{2}\right) b c}\right]}
\end{array}
$$

At low absorbances

$$
d A / d(b c)_{b c \rightarrow 0}=\frac{a_{1}+r a_{2}}{1+r}
$$

whereas when $b c$ becomes large, $10^{a_{1} b c} \gg 10^{a_{2} b c}$ and the limiting slope is

$$
d A / d(b c)_{b c_{\rightarrow \infty}}=a_{2} .
$$

Thus, the limiting absorptivity at low absorbances is is a weighted average of $a_{1}$ and $a_{2}$ while, at higher absorbances, it is equal to $a_{2}$, the smaller of the individual absorptivities.

The theory for the correction of spectral bandpass errors has been developed by Hardy and Young [4], Eberhardt [5], and Broderson [6]. Rigorous calculation requires integration of the relation

$$
A_{\mathrm{obs}}=\log \frac{\int I_{\lambda} S_{\lambda} d \lambda}{\int I_{\lambda} S_{\lambda} 10^{-A} d \lambda}
$$

where $I_{\lambda}$ is the incident intensity and $S_{\lambda}$ is the spectral sensitivity of the detector. Equation (7) emphasizes the fact that the observed absorbance depends not only on the shape of the absorption curve, but also on the wavelength distribution of the source and the detector response. If $I_{\lambda} S_{\lambda}$ is constant over the wavelength interval used, approximate corrections for spectral bandpass may be calculated by assuming a Gaussian shape for the absorption peak and a triangular slit function for the instrument. Some calculations are given in table 1 based on these assumptions. The tabulated values of $A_{\text {obs }} / A$ agree closely with those observed experimentally for $A$ up to 1 . As shown by Broderson [6] however, for values of RBW larger than $0.5, A_{\text {obs }} / A$ also depends on $A$ and the above treatment is no longer applicable.

\section{Stray Light}

Stray light is defined as any light outside the spectral region isolated by the monochromator that reaches the detector. It is produced by scatter from the optics and 
TABLE 1. Dependence of $A_{\text {obs }}$ on spectral bandpass at an absorption maximum under idealized conditions (see text)

$\begin{array}{cccc}\mathrm{RBW}^{\mathrm{a}} & A_{\text {obs }} / A & \mathrm{RBW}^{\mathrm{a}} & A_{\text {obs }} / A \\ & & & \\ 0.0100 & 0.99995 & 0.0800 & 0.9970 \\ .0200 & .9998 & .0900 & .9962 \\ .0300 & .9995 & .1000 & .9954 \\ .0400 & .9992 & .2000 & .9819 \\ .0500 & .9988 & .3000 & .9604 \\ .0600 & .9983 & .4000 & .9321 \\ .0700 & .9977 & .5000 & .8987\end{array}$

${ }^{a}$ Relative bandwidth: Ratio of spectral bandwidth to half bandwidth of fully resolved peak.

walls of the monochromator and is present in varying amounts in all spectrophotometers.

Stray light can lead to varied problems in spectrophotometry. Spurious absorption bands may arise in some cases. More frequently, however, deviations from the Lambert-Beer law are produced. These deviations are positive if the stray light is absorbed and negative if it is not.

Extensive literature exists on the detection, ineasurement and mimization of stray light. Several of the more useful papers are those by Hogness, Zscheile and Sidwell [7], Perry [8], Slavin [9], and Poulson [10] in which additional references may be found.

The amount of stray light present is proportionally large in those wavelength regions where the transmission of the monochromator, the source intensity or the detector sensitivity are relatively low. These regions, which should first be checked, are 200-230 $\mathrm{nm}$ and 600-700 $\mathrm{nm}$. If a tungsten lamp must be used in the range $350-400 \mathrm{~nm}$, a visible cutoff filter should always be employed.

The quantitative assessment of stray light requires the use of extremely sharp cutoff filters. Slavin [9] and Poulson [10] have described a number of liquid and solid filters that may be used. Aqueous solutions of the alkali halides, for example, are extremely useful in the ultraviolet. Care must be taken, however, that light leaks in the cuvet compartment are not contributing to the observed results. The apparent stray light will not vary appreciably with slitwidth if only instrumental stray light is present. In a quick test for light leaks, the apparent stray light will decrease rapidly as the slits are opened.

The stray light error encountered most frequently in spectrophotometry produces a decrease in an absorption peak and leads to negative deviations from the Lambert-Beer law. If it is assumed that none of the stray light is absorbed by the sample, the measured absorbance is related to the true transmittance by the expression [9]

$$
A_{\text {obs }}=\log [(1-T) S+T]^{-1}
$$

where $S$ is the instrumental stray light expressed as a fraction. The effects of several levels of unabsorbed stray light on absorbance are given in table 2. Most samples absorb sufficiently in other regions of the spectrum to filter out a proportion of the stray light. Thus, indirect estimates of instrumental stray light based on deviations from linearity are generally low.

TABLE 2. Effect of unabsorbed stray light on absorbance

\begin{tabular}{rccc}
$A$ & \multicolumn{3}{c}{$A_{\text {obs }}$} \\
\cline { 2 - 4 } & $S=0.0001$ & $S=0.001$ & $S=0.01$ \\
0.1 & 0.1000 & 0.0999 & 0.0989 \\
.5 & .4999 & .4990 & .4907 \\
1.0 & .9996 & .9961 & .9626 \\
1.5 & 1.499 & 1.487 & 1.384 \\
2.0 & 1.996 & 1.959 & 1.701
\end{tabular}

\section{Nonparallel Incident Radiation}

A perfectly parallel beam of radiation must come from a point source and can carry only an infinitesimal amount of energy. The light beam in a spectrophotometer always has some finite angular size. As a result, the average light path is greater than the perpendicular distance between the cuvet faces. Meehan [3] has considered the case in which the incident radiation is convergent or divergent in one dimension such as corresponds, respectively, to radiation focused by a cylindrical lens or leaving a narrow slit. If $\Theta$ and $R$ are the angles of incidence and refraction, respectively, the path length of the extreme ray (fig. 2) is $b / \cos R$ and the absorbance of this ray is $A / \cos R$. Other rays enter at smaller angles and the observed absorbance is given by

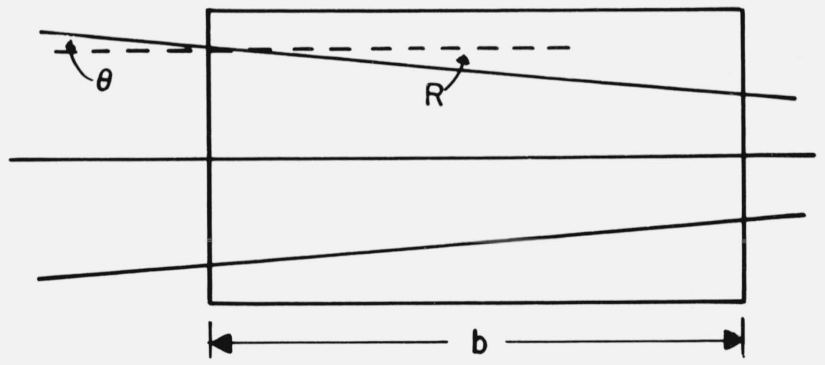

FIGURE 2. Nonparallel incident radiation [3]. Reprinted by permission of John Wiley \& Sons, Incorporated.

$$
A_{\mathrm{obs}}=A / R_{\max } \int_{0}^{R_{\max }} 1 / \cos R d R .
$$

For this relation to hold, the incident beam must be uniform over its cross section. Evaluation of this integral for $R_{\max }$ of $2-10^{\circ}\left(\Theta_{\max }=2.7^{\circ}-13.4^{\circ}\right)$ gives the following percent errors in $A$ (table 3 ). Thus, for angles of incidence up to 5 degrees, the absorbance error is less than 0.1 percent.

\section{E. Multiple Reflections}

On passage of light through a cuvet containing solvent or sample solution, some radiation is reflected 
TABLE 3. Dependence of absorbance error on nonparallelism of incident radiation

$\begin{array}{ccc}R_{\text {max }}, \text { degrees } & \Theta_{\text {max }}, \text { degrees } & \text { Percent error in } A \\ 2 & 2.7 & 0.020 \\ 4 & 5.3 & .081 \\ 6 & 8.0 & .18 \\ 8 & 10.7 & .33 \\ 10 & 13.4 & .51\end{array}$

at each of the two air-glass and the two glass-liquid surfaces. For perpendicular incidence, the fraction $f$ reflected on passing from a medium of refractive index $n_{1}$ to a second having retractive index $n_{2}$ is given by the Fresnel expression

$$
f=\left[\frac{n_{1}-n_{2}}{n_{1}+n_{2}}\right]^{2}
$$

For an air-glass surface, $f=0.04$ and for a glassliquid surface, $f=0.0035$. When more than one surface is involved, the effects of multiple reflections must be considered. The essential question when dealing with liquid filters is whether the solvent completely compensates for such reflections. According to Goldring et al. [11], it does not. They consider the case where the reflections from all surfaces perpendicular to the light beam on the two sides of the sample are grouped together to form two effective reflection coefficients, $r_{1}$ and $r_{2}$, as shown in figure 3 . Considering only first and second order reflections, the observed absorbance is
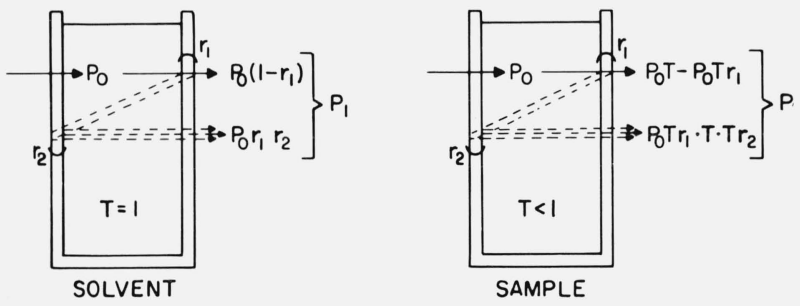

FIGURE 3. Internal multiple reflections [11]. Reprinted by permission of the American Chemical Society.

$$
A_{\mathrm{obs}}=\log \frac{P_{1}}{P_{2}}=\log \frac{P_{0}}{P_{0} T} \frac{\left(1-r_{1}+r_{1} r_{2}\right)}{\left(1-r_{1}+r_{1} r_{2} T^{2}\right)}
$$

which, after transformation and series expansion, can be reduced to the following expression:

$$
A_{\mathrm{obs}}=A+0.4343\left(1-T^{2}\right) \frac{r_{1} r_{2}}{1-r_{1}} .
$$

Considering only the reflections from the two cuvet faces and that $r_{1}=r_{2}=0.05$, the variation of $A_{\text {obs }}$ with $A$ is
A
0.1
0.2
0.5
1.0
2.0
A obs
0.1004
0.2007
0.5010
1.0011
2.0011

Thus, because of internal multiple reflections, the measured absorbance should always be larger than the true absorbance with the percentage difference being greatest at low absorbances. Verification of these deviations is difficult experimentally. Goldring et al. [11], however, have suggested ways of minimizing reflection effects. These include positioning the cuvet at a small angle to the beam and stopping down the detector surface, immersing the cuvet in a fluid contained in a larger rectangular cuvet turned at an angle to the beam, or by using a cuvet with prismatic windows. In each case, the effective path length must be determined separately. Other alternatives consist , of using cuvets constructed of absorbing materials or immersion of a glass filter into the sample. For a limited wavelength range, reflection errors can also be reduced by coating the external window surfaces with anti-reflection layers.

In addition to reflections from the cuvets, reflections from other surfaces must also be considered. Gibson [1] has pointed out that reflections may occur from the surfaces of the slit and detector and has suggested a means for checking this source of error. A thin glass plate is placed in its normal position at right angles to the beam and then at a small angle from this position. In the second position the reflected energy is directed out of the beam while scarcely affecting the true absorbance.

\section{F. Cuvets}

The majority of absorbance measurements are performed on solutions and, in such instances, the cuvet becomes an integral part of the measurement system. Presently, the uncertainty in the length of the light path can be a limiting factor in the determination of molar absorptivity. Nonparallelism of the end windows can be of even greater consequence. However, the effect can be minimized by using the same cuvet orientation for all measurements. The uncertainty in path length is nevertheless greater.

Cuvets are available in a variety of shapes and sizes and may be made of glass or silica. Construction remains largely an art and cuvets may vary considerably in their quality. Two methods of assembly are commonly used. These are: (1) fusion using only heat and (2) the use of intermediate, low-melting glasses. At present, each has its disadvantage. The first technique is the more desirable, but our experience, primarily with rectangular cuvets, indicates that the edges are not always completely fused. These surfaces exhibit capillarity and may become serious sources of contamination. Under such conditions, the cleaning of these cuvets is difficult, if not impossible. The use of low-melting fluxes on the other hand can produce strains because of differences in coefficients of expansion and cuvets so constructed are generally more fragile.

Cuvets are frequently offered in matched sets. This may be considered more of a convenience than a necessity since this terminology is normally used only to describe the transmission of the window material. 
Path length and parallelism of end plates are of more fundamental importance. Unfortunately, no generally accepted tolerances have been established in this country for the construction of cuvets. The British Standards Institution, however, has published a set of specifications [12] which merit our consideration and possible adoption. They recommend that the path length be specified to $\pm 0.02 \mathrm{~mm}$ and the end windows be flat over a defined beam area to four Newton fringes per centimeter in mercury green light. It should be feasible for greater accuracy, especially for the $10 \mathrm{~mm}$ cuvets, to calibrate a limited number by appropriate metrology techniques to $\pm 0.01 \mathrm{~mm}$.

\section{Evaluation of Selected Liquid Filters}

This section is a report of our efforts to develop well characterized liquid absorbance standards. Three general types of liquid filters are discussed. These are (1) individual solutions of high purity materials, (2) empirical mixtures and (3) aqueous solutions of organic dyes. Much of the emphasis has been placed on determining the optimum conditions for preparation of these filters and, once established, what the absorbing species or ionic compositions of these systems are. By combining this information with the instrumental considerations developed in the first part of this paper, it is hoped that the resulting data represent a step toward obtaining more meaningful absorptivity measurements.

\section{A. Instrumentation}

Absorbance measurements at a fixed wavelength were performed manually on a high precision doublebeam spectrophotometer provided with a double monochromator. The accuracy of the photometric scale of this instrument was established with the NBS high-accuracy spectrophotometer described by Mavrodineanu [13]. The wavelength scale was checked with a mercury lamp. Potassium halide solutions [9, 10] were used to assess stray light in the ultraviolet.

Room temperature was maintained between 24 to $26{ }^{\circ} \mathrm{C}$. The cuvet compartment and jacketed holders were thermostated by a circulating water bath. Copperconstantan thermocouples were used to measure temerature differences between the bath and the sample solution.

An electronic feeler gauge [13] was used to measure the path length of the $10 \mathrm{~mm}$ rectangular cuvets normally used. Solutions, assumed to obey Beer's law, were used for calibrating the $1 \mathrm{~mm}$ cuvets.

The accuracy of the microbalance was established with NBS-calibrated weights. Class A, 1-liter volumetric flasks were checked gravimetically. All dilutions were subsequently made by volume. To minimize errors from cell positioning, borosilicate, Pasteurtype pipets were used to transfer solutions to and from the cuvets.

\section{B. Individual Solutions of High Purity Compounds}

1. Potassium Dichromate. Numerous attempts have been made to use chormium (VI) solutions as ultraviolet absorbance standards. In the early studies [7, 14, 15, 16, 17] alkaline solutions of potassium chromate were preferred. More recently, potassium dichromate in slightly acidic media has been described $[18,19,20]$. The absorption spectra of these two systems are quite different with the latter giving the more desirable arrangement of maxima and minima (fig. 4).

The approximate composition of chromium (VI) solutions may be derived from the following equilibria:

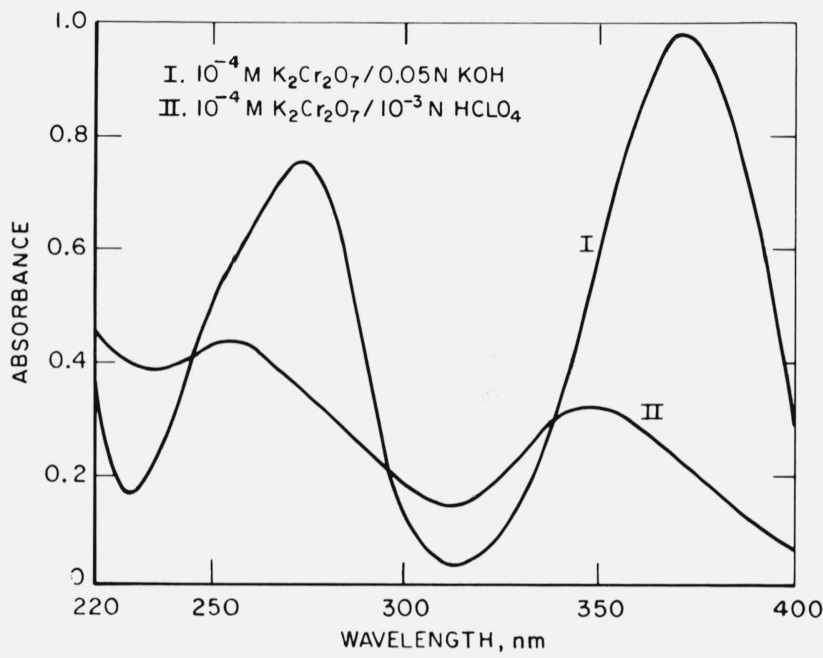

Figure 4. Absorption spectra of $10^{-4} \mathrm{M} \mathrm{Cr}(\mathrm{VI})$ in $0.05 \mathrm{~N} \mathrm{KOH}$

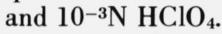

$$
\begin{gathered}
\mathrm{H}_{2} \mathrm{CrO}_{4} \stackrel{K_{1}}{=} \mathrm{H}^{+}+\mathrm{HCrO}_{4}^{-} \\
\mathrm{HCrO}_{4}^{-} \stackrel{K_{2}}{=} \mathrm{H}^{+}+\mathrm{CrO}_{\overline{4}}^{-} \\
2 \mathrm{HCrO}_{4}^{-} \stackrel{K_{3}}{=} \mathrm{Cr}_{2} \mathrm{O}_{\overline{7}}+\mathrm{H}_{2} \mathrm{O} .
\end{gathered}
$$

Some values reported for the equilibrium constants $K_{1}, K_{2}$, and $K_{3}$ at $25{ }^{\circ} \mathrm{C}$ are as follows:

$$
\begin{aligned}
& K_{1}=0.16[21] \\
& K_{2}=3.2 \times 10^{-7}[22] \text { and } 3.0 \times 10^{-7}[23] \\
& K_{3}=43.7[21], 35.5[24] \text { and } 33.0[25] .
\end{aligned}
$$

Thus, at a pH greater than 10 , chromium (VI) exists almost entirely as $\mathrm{CrO}_{\overline{4}}$ ions while, in weakly acidic solutions, the predominant species is $\mathrm{HCrO}_{4}^{-}$which partially dimerizes to $\mathrm{Cr}_{2} \mathrm{O}_{\overline{7}}$. The amount of dimer will increase with increasing chromium concentration. The formation of $\mathrm{H}_{2} \mathrm{CrO}_{4}$ or $\mathrm{CrO}_{\overline{4}}$ can be essentially eliminated by maintaining the acidity near pH 3. 
Much of the uncertainty that has arisen from the use of acidic potassium dichromate solutions as potential absorbance standards can be attributed to the dimerization reaction (eq (15)). It is primarily this equilibrium which leads to the observed deviations from Beer's law. Because of the range of values reported for $K_{3}$, one of the first objectives of the present study was to redetermine this constant. The spectrophotometric method was chosen and is described in some detail below.

a. Spectrophotometric Determination of the Dimerization Constant for: $2 \mathrm{HCrO}_{\overline{4}}=\mathrm{Cr}_{2} \mathrm{O}_{\overline{7}}$ $+\mathrm{H}_{2}$ O. If $\mathrm{HCrO}_{4}$ and $\mathrm{Cr}_{2} \mathrm{O}_{\overline{7}}$ are the only $\mathrm{Cr}(\mathrm{VI})$ species preseni with molar absorptivities $\epsilon_{1}$ and $\epsilon_{2}$, respectively, the apparent molar absorptivity, $\epsilon_{m}$, will be given by

$$
\epsilon_{m}=(1-\alpha) \epsilon_{1}+1 / 2 \cdot \alpha \epsilon_{2}
$$

where $\alpha$ is the fraction of total chromium in the dichromate form. From eq (15) the thermodynamic equilibrium constant of the dimerization reaction is

$$
K_{3}=\frac{\left[\mathrm{Cr}_{2} \mathrm{O}_{\overline{7}}\right]}{\left[\mathrm{HCrO}_{4}^{-}\right]^{2}} \cdot \frac{\gamma_{2}}{\gamma_{1}^{2}}
$$

or, in terms of $\alpha$

$$
K_{3}=\frac{\alpha}{2(1-\alpha)^{2} \mathrm{Cr}_{T}} \cdot \frac{\gamma_{2}}{\gamma_{1}^{2}}
$$

where $\gamma_{1}$ and $\gamma_{2}$ are the activity coefficients of $\mathrm{HCrO}_{\overline{4}}$ and $\mathrm{Cr}_{2} \mathrm{O}_{\overline{7}}$, respectively, and $\mathrm{Cr}_{T}$ is the total chromium concentration. Because the ionic strength never exceeded 0.01 , the activity coefficients may be treated by the Debye-Hückel expression [25]

$$
-\log \gamma_{i}=\frac{A Z_{i}^{2} I^{1 / 2}}{1+I^{1 / 2}}
$$

where $Z$ is the ionic charge, $I$ is the ionic strength and $A$ has a value of $0.509 \mathrm{l} / \mathrm{mol}$ at $25^{\circ} \mathrm{C}$. Equations (16) and (18) can be rewritten to give, respectively,

$$
\epsilon_{m}=\alpha\left(1 / 2 \epsilon_{2}-\epsilon_{1}\right)+\epsilon_{1}
$$

and

$$
\log K_{3}=\log \frac{\alpha}{2(1-\alpha)^{2} \mathrm{Cr}_{T}}-\frac{2 A I^{1 / 2}}{1+I^{1 / 2}}
$$

Assuming a value of $K_{3}$, one can calculate from eq (21) the $\alpha$ values at various total chromium concentrations. If the choice of $K_{3}$ is correct, the measured values of $\epsilon_{m}$ should lie on a straight line of slope (1/2 $\left.\epsilon_{2}-\epsilon_{1}\right)$ and intercept $\epsilon_{1}$, as seen from eq (20). The best value of $K_{3}$ is then determined by the method of least squares.

\section{Experimental Procedure}

The chromium (VI) solutions used in the subsequent studies were prepared from NBS SRM-136c, potassium dichromate, which had been dried at $110{ }^{\circ} \mathrm{C}$ for two hours. The distilled water was shown to be free of reducing impurities by titration with a dilute potassium permanganate solution. Perchloric acid was used to maintain the $\mathrm{pH}$ at $3.0 \pm 0.1$.

The optimum wavelengths for the determination of $K_{3}$ were chosen as follows: Two solutions were prepared, one containing $391 \mathrm{mg} \mathrm{K}_{2} \mathrm{Cr}_{2} \mathrm{O}_{7} / 1$ and the other, $40.0 \mathrm{mg} \mathrm{K} \mathrm{Cr}_{2} \mathrm{O}_{7} / 1$. The former was transferred to a $1.023 \mathrm{~mm}$ cuvet and the latter to a $10.00 \mathrm{~mm}$ cuvet. A differential scan was then made on a recording spectrophotometer equipped with a $0-0.1$ absorbance (full scale) slidewire, using the less concentrated solution as the reference. The resulting spectrum is shown in figure 5. Relatively large differences in absorbance are seen in the wavelength regions near 275 and $385 \mathrm{~nm}$ even though the total number of chromium atoms in each light path is the same. Thus, it is in these two regions that the largest deviations from Beer's law should be observed. Three wavelengths were subsequently selected in each region for the determination of $K_{3}-390,385$ and 380 and 280, 275 and $270 \mathrm{~nm}$, respectively.

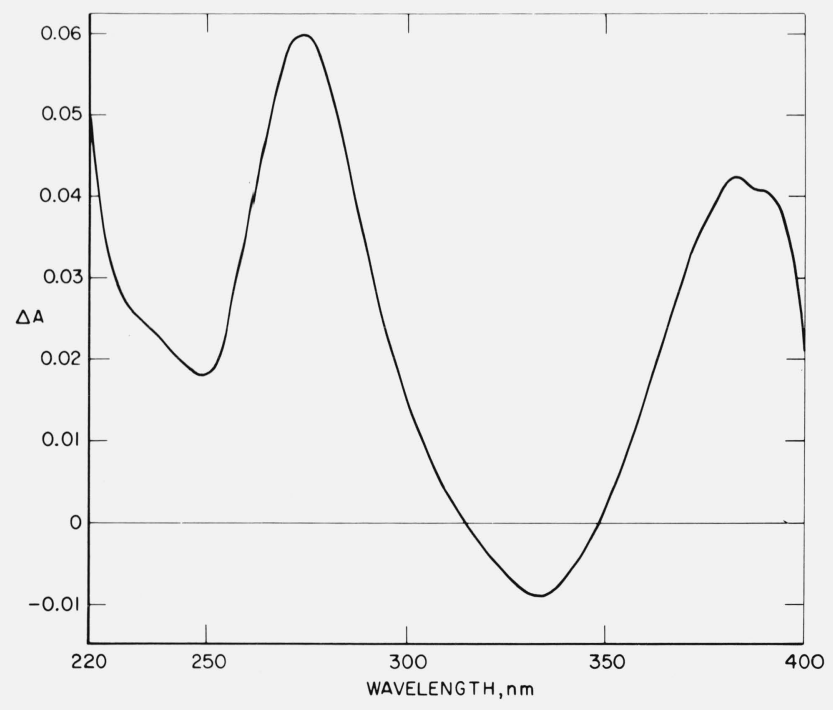

FigURE 5. Difference spectrum of $391 \mathrm{mg} \mathrm{K}_{2} \mathrm{Cr}_{2} \mathrm{O}_{7} / 1$ in $1.023 \mathrm{~mm}$ cuvet versus $40.0 \mathrm{mg} \mathrm{K} \mathrm{Cr}_{2} \mathrm{O}_{7} / 1$ in $10.00 \mathrm{~mm}$ cuvet; $\mathrm{pH}=3$.

\section{Results}

The apparent molar absorptivities calculated from absorbance measurements on the four chromium concentrations used for the determination of $K_{3}$ are given in table 4 . Using the method of least squares, these $\epsilon_{m}$ values were plotted against the $\alpha$ fractions calculated from eq (21) for various assumed values of $K_{3}$. The molar absorptivities were weighted according to the reproducibility of the absorbance measurements. A computer was used for all calculations. 
A typical graph of the residual standard deviation of the experimental $\epsilon_{m}$ values from the best straight line fit is shown in figure 6 for $K_{3}$ values of 28 through
36. The minimum in this curve is the best estimate of $K_{3}$ and, for the case shown, is 32.6 . The $K_{3}$ values at the six wavelengths are summarized in table 5 .

TABLE 4. Apparent molar absorptivities, $\epsilon_{m}$, of $\mathrm{K}_{2} \mathrm{Cr}_{2} \mathrm{O}_{7}$ solutions at $25{ }^{\circ} \mathrm{C} ; \mathrm{pH}=2.9\left(\mathrm{HClO}_{4}\right)$

$$
\underset{\mathrm{mg} / 1}{\mathrm{~K}_{2} \mathrm{Cr}_{2} \mathrm{O}_{7} \text { Conc. }}
$$

100.06

400.48

699.86

1000.27

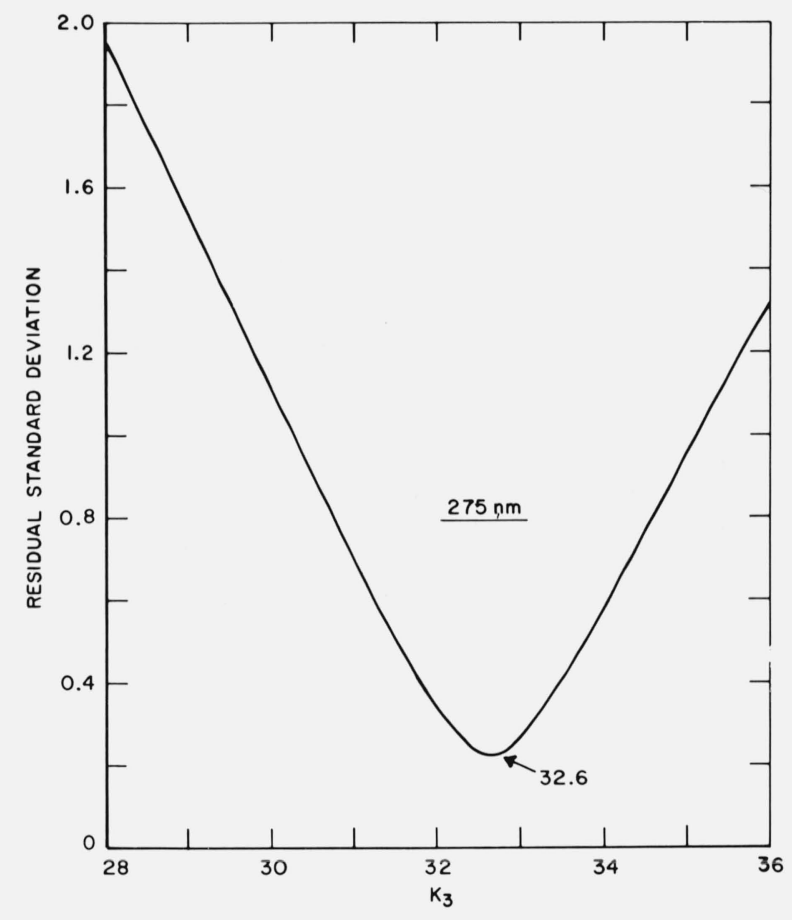

FIGURE 6. Least squares determination of $K_{3}$.

TABLE 5. $\mathrm{K}_{3}$ values at $25^{\circ} \mathrm{C}$ as determined at several wavelengths

$\begin{array}{cc}\lambda, \mathrm{nm} & K_{3} \\ & \\ 390 & 32.4 \\ 385 & 33.3 \\ 380 & 33.8 \\ & \\ 280 & 33.5 \\ 275 & 32.6 \\ 270 & 31.6 \\ & \text { Avg. } 32.9\end{array}$

Std. Dev. 0.8

Rel. Std. Dev. $2.5 \%$ $\epsilon_{m} \mathrm{l} / \mathrm{mol}^{-1} \mathrm{~cm}^{-1}$

$\begin{array}{rrrrrr}390 \mathrm{~nm} & 385 \mathrm{~nm} & 380 \mathrm{~nm} & 280 \mathrm{~nm} & 275 \mathrm{~nm} & 270 \mathrm{~nm} \\ & & & & & \\ 589.2 & 748.7 & 865.1 & 1579.3 & 1718.6 & 1881.0 \\ 714.1 & 878.6 & 997.8 & 1758.2 & 1914.4 & 2069.8 \\ 806.2 & 973.8 & 1094.0 & 1890.0 & 2053.5 & 2208.0 \\ 875.9 & 1045.6 & 1166.5 & 1988.2 & 2161.5 & 2313.6\end{array}$

b. Absorption Spectra of $\mathrm{HCrO}_{4}^{-}$and $\mathrm{Cr}_{2} \mathrm{O}_{7}^{\bar{*}}$. The absorbances of three solutions containing nominally 20,40 , and $60 \mathrm{mg} \mathrm{K}_{2} \mathrm{Cr}_{2} \mathrm{O}_{7} / 1(\mathrm{pH}=3.0 \pm 0.1)$ were measured in a $10.00 \mathrm{~mm}$ cuvet at $5 \mathrm{~nm}$ increments over the wavelength range of $220-400 \mathrm{~nm}$. A close approximation of $\epsilon\left(\mathrm{HCrO}_{4}^{-}\right)$was obtained by extrapolating the apparent molar absorptivities to zero chromium concentration. This extrapolation is simplified since the variation of $\alpha$ is nearly linear over this concentration range. Similar absorbance measurements were performed on three solutions containing $1000 \mathrm{mg} \mathrm{K}_{2} \mathrm{Cr}_{2} \mathrm{O}_{7} / 1$ using a $1.023 \mathrm{~mm}$ cuvet and the corresponding $\alpha$ value was calculated from eq (21), with $K_{3}=32.9$. The first approximations of $1 / 2$. $\epsilon\left(\mathrm{Cr}_{2} \mathrm{O}_{7}^{\overline{7}}\right)$ values were obtained by substituting the extrapolated $\epsilon\left(\mathrm{HCrO}_{4}^{-}\right)$results and the above $\alpha$ value into eq (20). The $\epsilon\left(\mathrm{HCrO}_{4}^{-}\right)$and $1 / 2 \cdot \epsilon\left(\mathrm{Cr}_{2} \mathrm{O}_{7}^{\overline{7}}\right)$ values were then refined by successive approximations. The calculated absorption spectra of these two ions are shown in figure 7.

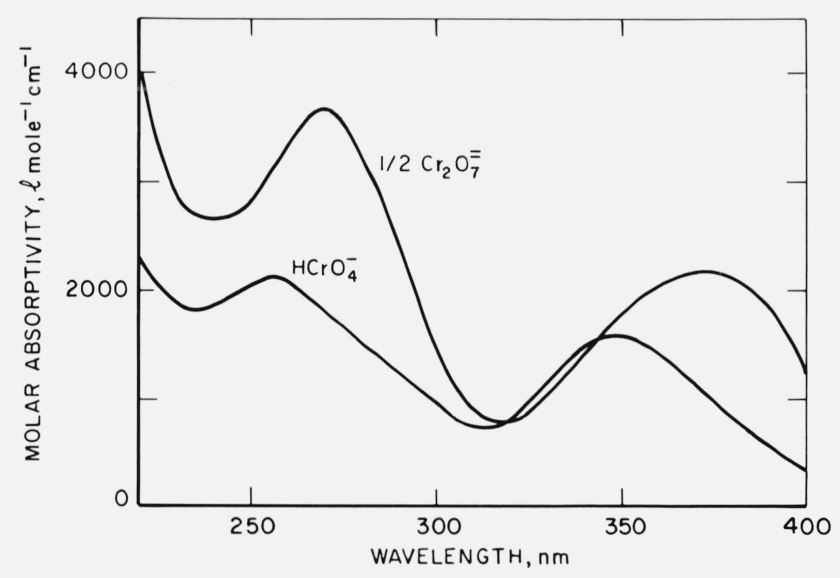

FigURE 7. Absorption spectra of $\mathrm{HCrO}_{\overline{4}}$ and $\mathrm{Cr}_{2} \mathrm{O}_{\overline{7}}$.

c. Molar Absorptivities of $\mathrm{HCrO}_{\overline{4}}$ and $\mathrm{Cr}_{2} \mathrm{O}_{\overline{7}}$ at $350,313,257$, and $235 \mathrm{~nm}$. As shown previously in figure 4 , the absorption spectrum of weakly acidic solutions of $\mathrm{K}_{2} \mathrm{Cr}_{2} \mathrm{O}_{7}$ exhibit maxima at 350 and $257 \mathrm{~nm}$ 
and minima at 313 and $235 \mathrm{~nm}$. These maxima and minima do not shift significantly over the concentration range of $20-100 \mathrm{mg} \mathrm{K}_{2} \mathrm{Cr}_{2} \mathrm{O}_{7} / 1$. This is considered a practical range for most applications since it yields absorbances of about $0.1-1.5$ for a $10 \mathrm{~mm}$ cuvet.

The molar absorptivities of $\mathrm{HCrO}_{4}^{-}$and $\mathrm{Cr}_{2} \mathrm{O}_{7}^{-}$at 350 , 313,257 , and $235 \mathrm{~nm}$ were determined by the procedure described above and are given in table 6 . The $\epsilon\left(\mathrm{HCrO}_{4}^{-}\right)$values are estimated to be accurate to \pm 0.5 percent. Because of the imprecision of the $K_{3}$ determination, the uncertainty of the dichromate molar absorptivity values may be as large as \pm 5 percent.

Table 6. Molar absorptivities, $\epsilon$, of $\mathrm{HCrO}_{4}^{-}$and $\mathrm{Cr}_{2} \mathrm{O}_{7}^{=}$

\begin{tabular}{rcccc} 
& \multicolumn{4}{c}{ at $25{ }^{\circ} \mathrm{C}$} \\
& $\epsilon, 1 \mathrm{~mol}^{-1}$ & $\mathbf{c m}^{-1}$ \\
\cline { 2 - 5 } & $350 \mathrm{~nm}$ & $313 \mathrm{~nm}$ & $257 \mathrm{~nm}$ & $235 \mathrm{~nm}$ \\
$\mathrm{HCrO}_{4}^{-}$ & 1576 & 711 & 2100 & 1804 \\
$1 / 2 \mathrm{Cr}_{2} \mathrm{O}_{7}^{=}$ & 1788 & 823 & 3156 & 2688
\end{tabular}

Table 7 shows the agreement between the experimental and calculated apparent molar absorptivities for five concentrations of potassium dichromate in dilute perchloric acid $(\mathrm{pH}=2.92 \pm 0.02)$. The experimental values are the averages obtained on five individual samples measured at each concentration. The 95 percent confidence limits for any given set of measurements was 0.1 percent. The $\alpha$ values used are also given. These are seen to vary nearly linearly over the range of chromium concentrations employed. d. Optimum pH and Choice of Acid. The chromium (VI) solutions used in this study were prepared in dilute perchloric acid media having a $\mathrm{pH}$ of about 3 . This acidity was selected because the existing equilibria data indicated this $\mathrm{pH}$ limited the formation of either $\mathrm{H}_{2} \mathrm{CrO}_{4}$ or $\mathrm{CrO}_{\overline{4}}$ to less than 0.1 percent of the total $\mathrm{Cr}$ (VI) concentration. Perchloric acid was chosen instead of sulfuric to prevent the formation of chromate-sulfate complexes. Tong and King [24] and Davies and Prue [25] noted slight differences in the absorbances of dilute perchloric and sulfuric acid solutions after correcting for differences in ionic strength. They attributed these differences to mixed complex formation. More recently, Haight et al. [26] have shown that the conversion of $\mathrm{HCrO}_{4}^{-}$to $\mathrm{CrSO}_{\overline{7}}$ is quantitative in $\mathrm{IM} \mathrm{HSO}_{4}$ solutions and that absorption spectrum of this complex is significantly different from the $\mathrm{HCrO}_{4}^{-}$spectrum.

Because most of the previous work reported in literature has been done in sulfuric acid, it was considered of interest to intercompare these two systems. The results are shown in each acid between $\mathrm{pH} 2$ and 3 . At $350 \mathrm{~nm}$ the results obtained in perchloric acid are consistently $0.1-0.2$ percent higher than in sulfuric; at $235 \mathrm{~nm}$, they are lower. The relatively large increase in absorptivity at $235 \mathrm{~nm}$ at $\mathrm{pH} 1.90$, together with the above considerations, suggest the formation of additional chromium (VI) species in systems employing dilute sulfuric acid solutions. (See table 8.)

e. Effect of Temperature. The absorbances of a solution containing $60 \mathrm{mg} \mathrm{K} \mathrm{Cr}_{2} \mathrm{O}_{7} / \mathrm{l}$ in dilute perchloric acid $(\mathrm{pH}=3)$ were measured over the temperature range of 17 to $37^{\circ} \mathrm{C}$. The percentage change in absorbance for wavelengths of $350,313,257$, and $235 \mathrm{~nm}$ is shown in figure 8 . The results are uncorrected for

TABLE 7. Experimental and calculated values (E, C) of the apparent molar absorptivity of $\mathrm{K}_{2} \mathrm{Cr}_{2} \mathrm{O}_{7}$ at $25{ }^{\circ} \mathrm{C}$; $\mathrm{pH}=2.9\left(\mathrm{HClO}_{4}\right)$

$$
\begin{gathered}
\mathrm{K}_{2} \mathrm{Cr}_{2} \mathrm{O}_{7} \text { Conc. } \\
\mathrm{mg} / \mathrm{l}
\end{gathered}
$$

20.22

40.09

60.12

80.17

99.92 $\alpha$

0.0090

0.0178

0.0262

0.0344

\begin{tabular}{|c|c|c|c|c|}
\hline & \multicolumn{4}{|c|}{$\epsilon_{m}, 1 \mathrm{~mol}-1 \mathrm{~cm}^{-1}$} \\
\hline & $350 \mathrm{~nm}$ & $313 \mathrm{~nm}$ & $257 \mathrm{~nm}$ & $235 \mathrm{~nm}$ \\
\hline $\mathrm{E}$ & 1577.6 & 713.5 & 2113.6 & 1814.7 \\
\hline $\mathrm{C}$ & 1577.9 & 711.9 & 2108.7 & 1812.1 \\
\hline Diff. & -0.3 & +1.6 & +4.9 & +2.6 \\
\hline $\mathrm{E}$ & 1579.9 & 713.3 & 2120.8 & 1820.2 \\
\hline $\mathrm{C}$ & 1579.8 & 713.0 & 2118.8 & 1819.7 \\
\hline Diff. & +0.1 & +0.3 & +2.0 & +0.5 \\
\hline $\mathrm{E}$ & 1581.4 & 713.8 & 2127.2 & 1827.1 \\
\hline C & 1581.5 & 713.8 & 2126.7 & 1827.2 \\
\hline Diff. & -0.1 & 0.0 & +0.5 & -0.1 \\
\hline $\mathrm{E}$ & 1584.0 & 715.0 & 2137.6 & 1835.8 \\
\hline C & 1583.3 & 714.8 & 2135.3 & 1834.4 \\
\hline Diff. & +0.7 & +0.2 & +2.3 & +1.4 \\
\hline $\mathrm{E}$ & 1585.5 & 715.6 & 2144.0 & 1841.5 \\
\hline $\mathrm{C}$ & 1584.0 & 715.0 & 2143.7 & 1841.4 \\
\hline Diff. & +1.5 & +0.6 & +0.3 & +0.1 \\
\hline
\end{tabular}

0.0423 
TABLE 8. Apparent absorptivities, $a$, of sulfuric and perchloric acid solutions of $\mathrm{K}_{2} \mathrm{Cr}_{2} \mathrm{O}_{7}$ at $25^{\circ} \mathrm{C} ; \mathrm{K}_{2} \mathrm{Cr}_{2} \mathrm{O}_{7}$ conc. $=0.050 \mathrm{~g} / \mathrm{l}$

$$
a, 1 \mathrm{~g}^{-1} \mathrm{~cm}^{-1}
$$

\begin{tabular}{lccccc}
\cline { 3 - 6 } & $\mathrm{pH}$ & $350 \mathrm{~nm}$ & $313 \mathrm{~nm}$ & $257 \mathrm{~nm}$ & $235 \mathrm{~nm}$ \\
& & & & & \\
$\mathrm{H}_{2} \mathrm{SO}_{4}$ & 1.90 & $10.71_{0}$ & $4.83_{7}$ & $14.44_{4}$ & $12.43_{7}$ \\
& 1.98 & $10.71_{2}$ & $4.83_{9}$ & $14.44_{0}$ & $12.41_{8}$ \\
& 2.20 & $10.72_{2}$ & $4.83_{9}$ & $14.42_{9}$ & $12.40_{2}$ \\
& 3.00 & $10.73_{3}$ & $4.84_{4}$ & $14.42_{7}$ & $12.38_{1}$ \\
$\mathrm{HClO}_{4}$ & 1.99 & $10.72_{7}$ & $4.84_{8}$ & $14.44_{8}$ & $12.39_{6}$ \\
& 3.08 & $10.74_{0}$ & $4.84_{5}$ & $14.43_{4}$ & $12.38_{3}$
\end{tabular}

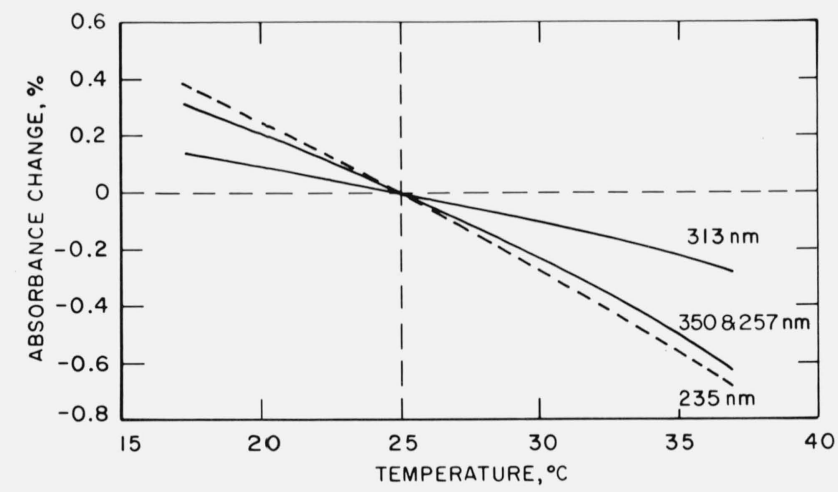

FIGURE 8. Change in absorbance with temperature for acidic solutions of $\mathrm{K}_{2} \mathrm{Cr}_{2} \mathrm{O}_{7} ; \mathrm{pH}=3\left(\mathrm{HClO}_{4}\right)$.

thermal expansion of the solvent. The absorption minimum at $313 \mathrm{~nm}$ exhibits the smallest temperature dependence $\left(-0.02\right.$ percent per $\left.{ }^{\circ} \mathrm{C}\right)$ while the maxima at 350 and $257 \mathrm{~nm}$ and the minimum at $235 \mathrm{~nm}$ have temperature coefficients of -0.05 percent per ${ }^{\circ} \mathrm{C}$ over the range 20 to $30^{\circ} \mathrm{C}$.

f. $\mathrm{K}_{2} \mathrm{Cr}_{2} \mathrm{O}_{7}$ in $0.5 \mathrm{M} \mathrm{Na}_{2} \mathrm{HPO}_{4}$ and $0.05 \mathrm{M} \mathrm{KOH}$. To overcome some of the difficulties in handling strongly alkaline chromate solutions, Johnson [27] has recommended dissolving $\mathrm{K}_{2} \mathrm{Cr}_{2} \mathrm{O}_{7}$ in $0.05 \mathrm{M} \mathrm{Na}_{2} \mathrm{HPO}_{4}$ at $\mathrm{pH}$ 9. The apparent molar absorptivities obtained in this medium and in $0.05 \mathrm{M} \mathrm{KOH}$ are given in table 9. As seen from the data, both systems appear to exhibit deviations from Beer's law of about three parts per thousand over the concentration range studied. Although this deviation is the same magnitude and direction predicted from uncompensated internal multiple reflections discussed previously, we have not been able to demonstrate experimentally that such reflections are responsible for the observed results. Studies in which the cuvet windows are coated with various antireflection layers are continuing however.
TABLE 9. Apparent molar absorptivity of potassium chromate in $0.05 M \mathrm{Na}_{2} \mathrm{HPO}_{4}$ and $0.05 M$ $\mathrm{KOH}$ at $25^{\circ} \mathrm{C}$

$0.05 \mathrm{M} \mathrm{Na}_{2} \mathrm{HPO}_{4}$

$\mathrm{K}_{2} \mathrm{CrO}_{4}$ Conc.
$M \times 10^{5}$
7
14
21

\begin{tabular}{ccc} 
& \multicolumn{2}{c}{$\epsilon_{m}, 1 \mathrm{~mol}^{-1} \mathrm{~cm}^{-1}$} \\
\cline { 2 - 3 } $\mathrm{pH}$ & $373 \mathrm{~nm}$ & $274 \mathrm{~nm}$ \\
& & \\
9.2 & $482_{7}$ & $370_{3}$ \\
9.1 & $482_{0}$ & $369_{7}$ \\
9.1 & $481_{3}$ & $369_{2}$
\end{tabular}

$0.05 M \mathrm{KOH}$

$\begin{array}{rrrr}7 & \ldots \ldots \ldots \ldots \ldots & 483_{0} & 370_{5} \\ 14 & \ldots \ldots \ldots \ldots \ldots & 482_{4} & 369_{8} \\ 21 & \ldots \ldots \ldots \ldots \ldots & 481_{4} & 369_{1}\end{array}$

From a consideration of the equilibrium data, the absorbances in the two systems should be nearly identical. The ionic strength of the $0.05 M \mathrm{Na}_{2} \mathrm{HPO}_{4}$ is 0.15 and, from Neuss and Rieman's work [22], the ionization constant for the reaction $\mathrm{HCrO}_{4}^{-}=\mathrm{H}^{+}+\mathrm{CrO}_{\overline{4}}^{-}$

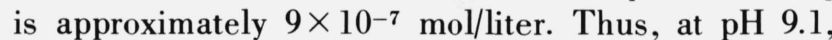
only about 1 in 1000 chromium atoms is present as $\mathrm{HCrO}_{\overline{4}}^{-}$. Since this species is less absorbing than $\mathrm{CrO}_{\overline{4}}$ at 373 and $274 \mathrm{~nm}$, the apparent molar absorptivities in $0.05 M \mathrm{Na}_{2} \mathrm{HPO}_{4}$ should agree with those obtained in $0.05 \mathrm{M} \mathrm{KOH}$ to within 0.1 percent.

The absorbance of alkaline chromate solutions decreases with increasing temperature at both absorption peaks. Between 17 and $37^{\circ} \mathrm{C}$, the temperature coefficient at $373 \mathrm{~nm}$ is -0.09 percent per ${ }^{\circ} \mathrm{C}$; at $274 \mathrm{~nm}$, it is -0.06 per ${ }^{\circ} \mathrm{C}$.

2. Potassium Nitrate. Aqueous solutions of potassium nitrate exhibit a nearly symmetrical absorption peak with $\lambda_{\max }$ at $302 \mathrm{~nm}$. This system has been studied extensively by Vandenbelt [14] and by the British Photoelectric Spectrometry Group in two collaborative tests [28, 29]. Molar absorptivities reported vary from 7.06 to 7.20 liter $\mathrm{mol}^{-1} \mathrm{~cm}^{-1}$. This range of values undoubtedly results in part from the fact that $\mathrm{KNO}_{3}$ solutions deviate significantly from Beer's law.

Careful reexamination of this system has yielded the following apparent molar absorptivities (table 10). These are seen to decrease rather markedly with increasing potassium nitrate concentration. Several factors conceivably contribute to this behavior. In addition to possible multiple reflection effects already discussed some ionic interactions are undoubtedly possible in this system because of the relatively high concentrations of solute required coupled with the fact that the $\mathrm{N}-\mathrm{O}$ bond in the nitrate ion has some polar character.

The potassium nitrate used in the above study was analyzed for commonly encountered impurities. After drying at $110^{\circ} \mathrm{C}$, the water content was less than 0.02 percent. Flame emission analyses [31] indicated the following levels of alkali and alkaline earth impurities 
(in parts-per-million): $\mathrm{Li}(<0.2) ; \mathrm{Rb}$ (13); $\mathrm{Mg}(0.2)$; $\mathrm{Ca}(1) ; \mathrm{Sr}(4)$ and $\mathrm{Ba}(<2)$.

At $302 \mathrm{~nm}$, the absorbance of $\mathrm{KNO}_{3}$ solutions decreases with increasing temperature. Over the range 17 to $37{ }^{\circ} \mathrm{C}$, the temperature coefficient is -0.14 percent per ${ }^{\circ} \mathrm{C}$.

Solutions stored for up to six months showed no measurable change $(\leqslant 0.1$ percent $)$ in absorbance. Edisbury [29] has cautioned, however, that some solutions may develop bacterial whiskers on standing. Sterilization may be effected by prior boiling of the distilled water.

TABLE 10. Apparent molar absorptivity, $\epsilon_{m}$, of aqueous solutions of potassium nitrate at $25^{\circ} \mathrm{C}$

$\begin{array}{cc} & \epsilon_{m}, \mathrm{l} \mathrm{mol}^{-1} \mathrm{~cm}^{-} \\ \mathrm{KNO}_{3} \text { Conc., } M & 302 \mathrm{~nm}^{\mathrm{a}} \\ & \\ 0.028 & 7.16_{0} \\ .056 & 7.14_{2} \\ .084 & 7.12_{7} \\ .112 & 7.10_{6} \\ .140 & 7.09_{1}\end{array}$

a Spectral bandpass $=1.0 \mathrm{~nm}$

3. Potassium Hydrogen Phthalate. High purity potassium hydrogen phthalate (KHP) is readily available. It is presently issued by the National Bureau of Standards as a primary acidimetric standard. Its use in the preparation of buffer solutions of known $\mathrm{pH}$ is well established. It has also been used as a spectral standard in the comparative evaluation of spectrophotometers [11, 32].

The absorbance of KHP solutions is dependent on acidity, as shown in figure 9. In the present study, dilute perchloric acid solutions were employed to minimize changes in ionic composition as a function of $\mathrm{pH}$. Acid concentrations much above $0.1 \mathrm{~N}$ could not be used because of the precipitation of potassium perchlorate. Subsequently, all solutions were prepared to contain $10 \mathrm{ml}$ of perchloric acid per liter with a $\mathrm{pH}$ of 1.3 .

Ringbom [21] has given the first ionization constant of phthalic acid as $1.6 \times 10^{-3}$ at $25{ }^{\circ} \mathrm{C}$ at an ionic strength of 0.1 . At the $\mathrm{pH}$ used, the absorbing system consisted of 97 percent phthalic acid and 3 percent hydrogen phthalate ions. Table 11 summarizes the absorptivity values obtained on these solutions.

Absorbance decreases at the $275.5 \mathrm{~nm}$ maximum and increases at the $262 \mathrm{~nm}$ minimum with increasing temperature. Over the range 17 to $37{ }^{\circ} \mathrm{C}$ the temperature coefficients are -0.05 percent and +0.05 percent per ${ }^{\circ} \mathrm{C}$, respectively.

Perchloric acid solutions of KHP (NBS-SRM 84,g) were examined for possible fluorescence, using a high sensitivity spectrofluorometer. With $280 \mathrm{~nm}$ excitation, a faint fluorescence was detected with $\lambda_{\max }$ at approximately $350 \mathrm{~nm}$. The possible effects of this fluorescence on the absorbance data remain to be established.

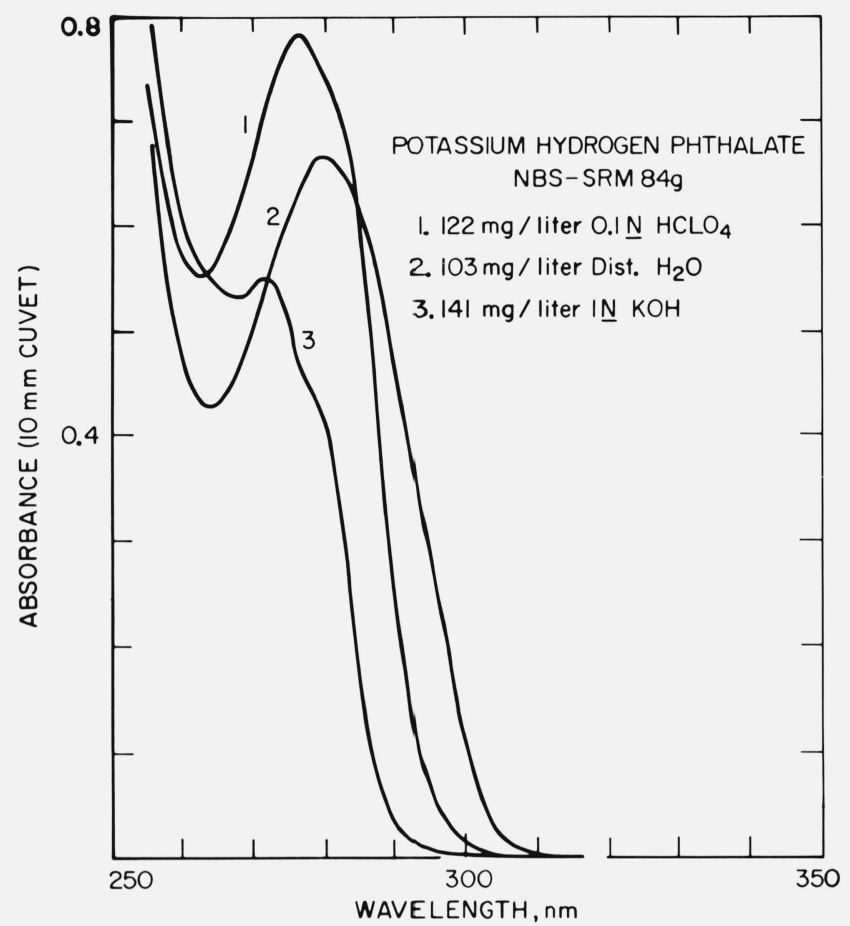

Figure 9. Absorption spectra of KHP solutions at different acidities.

TABLE 11. Apparent absorptivity, a, of potassium hydrogen phthalate in dilute perchloric acid at $25{ }^{\circ} \mathrm{C} ; 10 \mathrm{ml} \mathrm{HClO}$ /liter

\begin{tabular}{ccc} 
& \multicolumn{2}{c}{$\mathrm{a}, \mathrm{lg}^{-1} \mathrm{~cm}^{-1}$} \\
\cline { 2 - 3 } $\begin{array}{c}\text { NBS SRM 84g } \\
\text { Conc., g/l }\end{array}$ & $275.5 \mathrm{~nm}$ & $262 \mathrm{~nm}$ \\
0.034 & $6.33_{2}$ & $4.49_{4}$ \\
.142 & $6.31_{9}$ & $4.48_{9}$
\end{tabular}

4. Cobalt and Nickel Sulfates and Perchlorates. Aquo cobalt (II) and nickel (II) ions have relative broad absorption peaks with $\lambda_{\max }$ at 512 and 394 $\mathrm{nm}$, respectively (fig. 10). Solutions of either may serve as useful absorbance standards. Most of the attention to date, however, has been directed at cobalt sulfate which was first recommended by Gibson [1].

In this study, the apparent molar absorptivities of $\mathrm{Co}\left(\mathrm{H}_{2} \mathrm{O}\right)_{6}^{+2}$ and $\mathrm{Ni}\left(\mathrm{H}_{2} \mathrm{O}\right)_{6}^{+2}$ were examined in sulfate and perchlorate media. All solutions were prepared from the high purity metals by dissolution in $\mathrm{H}_{2} \mathrm{SO}_{4}-\mathrm{HNO}_{3}$ or $\mathrm{HClO}_{4}-\mathrm{HNO}_{3}$ acids. Nitrate was removed by repeated fuming until the acidity was reduced so that on dilution to volume, a $\mathrm{pH}$ of 1 could be obtained. The results obtained in the two acid media are given in table 12. The values in sulfate solution are significantly higher than in perchlorate media for both cobalt and nickel, suggesting that some complexation of these ions by $\mathrm{SO}_{4}^{=}$or $\mathrm{HSO}_{4}^{-}$has occurred. A differ- 


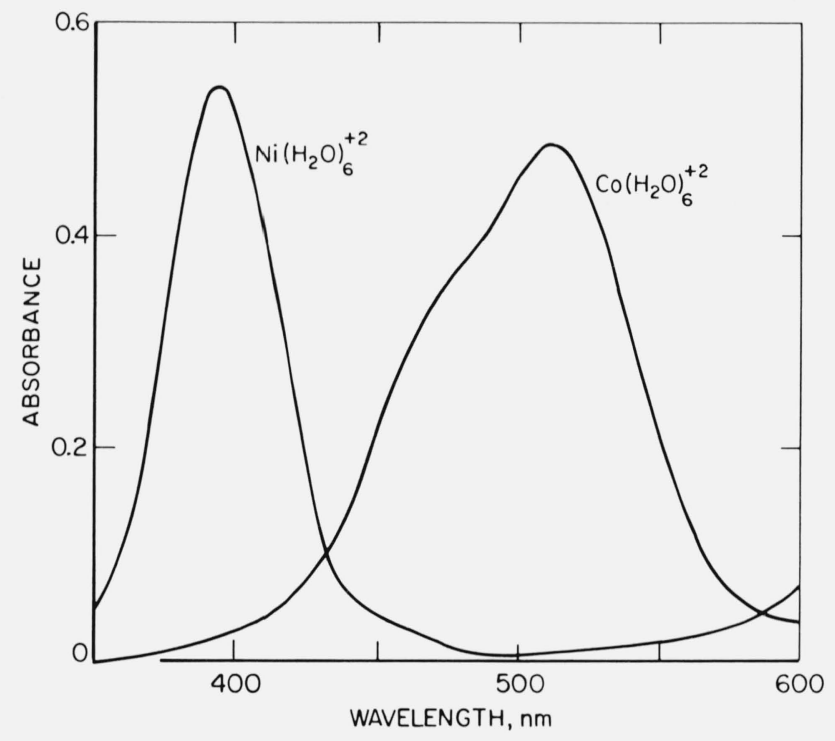

FIGURE 10. Absorption spectra of $\mathrm{Ni}\left(\mathrm{H}_{2} \mathrm{O}\right)_{6}^{+2}$ and $\mathrm{Co}\left(\mathrm{H}_{2} \mathrm{O}\right)_{6}^{+2}$.

TABLE 12. Apparent molar absorptivities, $\epsilon_{m}$ of acidic solutions of cobalt and nickel ions at $25{ }^{\circ} \mathrm{C} ; \mathrm{pH}=1.0$

\begin{tabular}{|c|c|c|}
\hline \multirow{2}{*}{$\begin{array}{c}\text { Co Conc. } \\
\mathrm{g} / \mathrm{l}\end{array}$} & \multicolumn{2}{|c|}{$\begin{array}{c}\epsilon_{m}(512 \mathrm{~nm}) \\
1 \mathrm{~mol}^{-1} \mathrm{~cm}^{-1}\end{array}$} \\
\hline & Sulfate & Perchlorate \\
\hline 2.4 & $4.88_{1}$ & $4.80_{3}$ \\
\hline 12.0 & $4.86_{9}$ & $4.79_{1}$ \\
\hline & \multicolumn{2}{|c|}{$\begin{array}{c}\epsilon_{m}(394 \mathrm{~nm}) \\
1 \mathrm{~mol}^{-1} \mathrm{~cm}^{-1}\end{array}$} \\
\hline $\mathrm{g} / 1$ & Sulfate & Perchlorate \\
\hline 2.3 & $5.16_{7}$ & $5.09_{0}$ \\
\hline 11.5 & $5.15_{4}$ & $5.07_{7}$ \\
\hline
\end{tabular}

ential spectrum of 0.2000 molar cobalt solution in sulfate against the same cobalt concentration in perchlorate media is shown in figure 11. In sulfate solution, the formation of a second cobalt species with $\lambda_{\max }=528 \mathrm{~nm}$ is indicated. Similar behavior was also observed for nickel.

The absorbances of cobalt and nickel solutions at their maxima are temperature dependent and increase with increasing temperature. Between 17 and $37{ }^{\circ} \mathrm{C}$ the temperature coefficients are 0.18 and 0.14 percent per ${ }^{\circ} \mathrm{C}$ at 512 and $394 \mathrm{~nm}$, respectively. To explain their nuclear magnetic resonance data on cobalt(II) solutions, Swift and Connick [33] have suggested that the octahedral $\mathrm{Co}\left(\mathrm{H}_{2} \mathrm{O}\right)_{6}^{+2}$ complex is in equilibrium with the tetrahedral $\mathrm{Co}\left(\mathrm{H}_{2} \mathrm{O}\right)_{4}^{+2}$ complex and that formation of the latter is favored by increasing temperature. By analogy with halide complexes, the tetrahedral

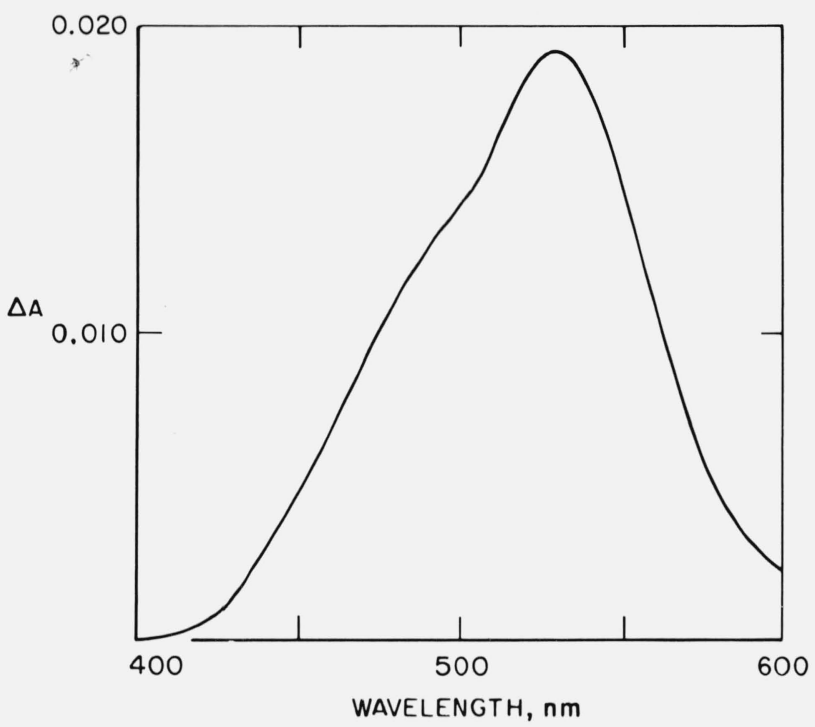

Figure 11. Differential spectrum of cobalt sulfate versus cobalt perchlorate; $10 \mathrm{~mm}$ cuvets; $\mathrm{pH}=1$.

configuration would be expected to be approximately one hundred times more absorbing than the octahedral complex. A very small shift in this equilibrium could result in a relatively large change in absorbance and thereby account for the large temperature coefficient of this system. The same explanation may also be valid for nickel solutions.

\section{Liquid Filters of Improved Optical Neutrality}

Two approaches have been used in an attempt to improve the optical neutrality and extend the wavelength range of liquid filters. One is based on the use of empirical mixtures, while the other employs watersoluble, organic "black" dyes.

In 1946, Thomson [34] described the preparation of a grey inorganic solution consisting of chromic, cobaltous and cupric sulfates and potassium dichromate. This solution, however, does not transmit below 300 $\mathrm{nm}$. To extend the wavelength range farther into the ultraviolet, a second exploratory solution (henceforth referred to as the NBS composite) was prepared in which the cupric and potassium dichromate components of the Thomson mixture were replaced by $p$ nitrophenol. The absorption spectra of these solutions are compared in figure 12 to a commonly used glass filter (Chance $\mathrm{ON}-10)$. The NBS composite was prepared in dilute sulfuric acid and had a $\mathrm{pH}$ of 1 . No fluorescence was observed under these conditions.

Over the range $250-600 \mathrm{~nm}$, the NBS composite exhibits several broad maxima and minima whose absorbances are less dependent on spectral bandpass than the Chance $\mathrm{ON}-10$ glass. Examples are given in figure 13 at two wavelengths for each.

The possible use of either Thomson solution or the NBS composite as an absorbance standard is limited by two factors, both of which arise from the presence of chromium(III) in these mixtures. First, 


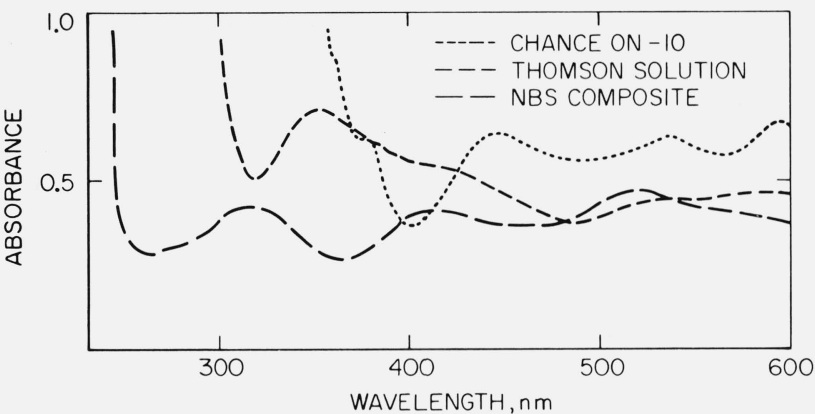

FIGURE 12. Absorption spectra of Thomas solution, an NBS composite and a Chance $\mathrm{ON}-10$ glass.

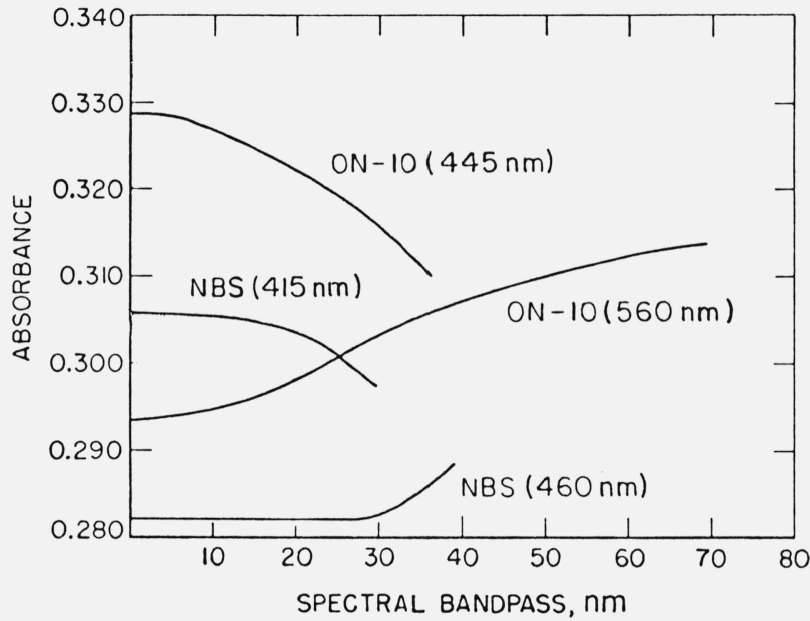

FIGURE 13. Variation of absorbance with spectral bandpass for NBS composite and Chance $\mathrm{ON}-10$ glass.

an initial "aging" of 6-8 weeks period is needed in order to achieve adequate spectral stability at room temperature. Secondly, and even more critical for our purpose, is that the absorbances of the aged solutions exhibit a nonreversible temperature dependence. They must therefore always be stored at the temperature at which they were aged.

Hall and Eyring [35] have studied the constitution of chromic salts in aqueous solution and have suggested that during the aging process $\mathrm{Cr}\left(\mathrm{H}_{2} \mathrm{O}\right)_{6}^{+3}$ ions polymerize to yield species of the type

$$
\left[\left(\mathrm{H}_{2} \mathrm{O}\right)_{5} \mathrm{Cr}-\mathrm{H}-\mathrm{O}-\mathrm{Cr}\left(\mathrm{H}_{2} \mathrm{O}\right)_{5}\right]^{+5},
$$

and

$$
\left[\left(\mathrm{H}_{2} \mathrm{O}\right)_{5}-\mathrm{Cr}-\stackrel{\mathrm{H}}{\mathrm{O}}-\mathrm{Cr}\left(\mathrm{H}_{2} \mathrm{O}\right)_{4}-\stackrel{\mathrm{H}}{\mathrm{O}}-\mathrm{Cr}\left(\mathrm{H}_{2} \mathrm{O}\right)_{5}\right]^{+7}
$$

in which the observed increase in acidity is explained by the formation of $-\mathrm{OH}$ bridges. Recent studies [36] have shown that temperature, initial $\mathrm{pH}$ and the type of anion present significantly affect the equilibrium composition. Although refluxing can reduce the aging period from several months to several hours, this is of no practical advantage since the high temperature products, on cooling, are no longer stable.

In addition to the investigation of empirical mixtures, several water-soluble organic dyes have also been studied. Some typical absorption spectra are shown in figure 14. All of these dyes have high absorptivities and the concentrations used were of the order of 50 milligrams per liter.

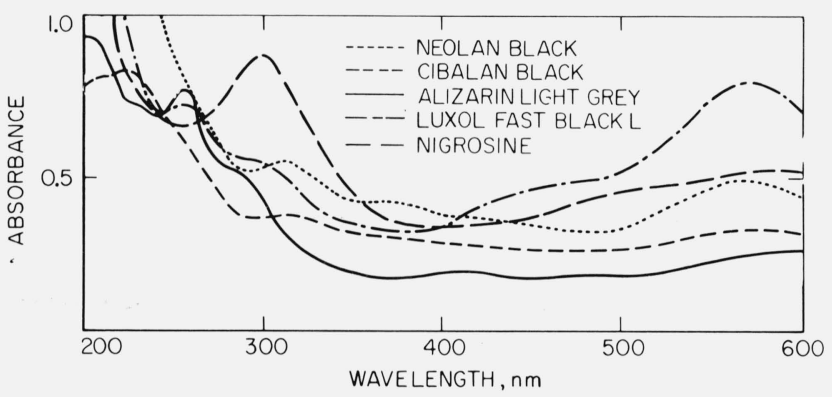

FigURE 14. Absorption spectra of aqueous solutions of selected dyes.

Cibalan Black [37], Neolan Black [37] and Alizarin Light Grey [38] were selected for further evaluation. Aqueous solutions of these dyes were found insensitive to $\mathrm{pH}$ over the range $2-9$, not affected by heat and relatively light fast. Solutions continuously exposed to fluorescent light exhibited an absorbance change of about 1 percent over a period of two months. These initial results appeared sufficiently promising to warrant purification and more extensive testing. Members of the Organic Chemistry Section have assisted in this effort. The purification of these dyes has proven extremely difficult, however, and yields of only a few hundred milligrams of each have been obtained. Much larger quantities are needed if these dyes are to be used as Standard Reference Materials. More efficient purification procedures are presently being sought.

\section{Standard Reference Material (SRM) 931}

The first liquid absorbance standard to be issued by the National Bureau of Standards is SRM 931. The preparation and certification of this Standard Reference Material are described below.

The filters were prepared by dissolving high purity cobalt and nickel in a mixture of nitric and perchloric acids. The weights of cobalt and nickel were chosen so that the absorbances of their aquo complexes were approximately equal at their absorption maxima. The absorbance of nitrate was adjusted to a comparable level by evaporation and subsequent addition 


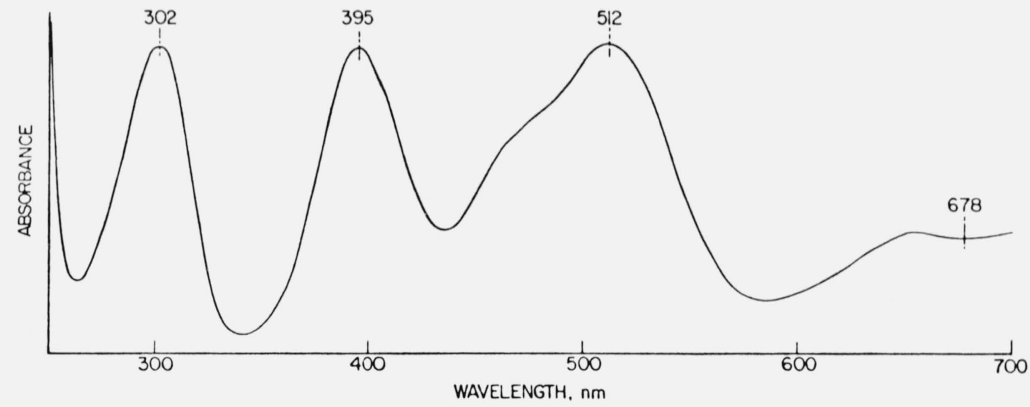

Figure 15. Typical absorption spectrum of SRM 931.

of small amounts of nitric acid. The final $\mathrm{pH}$ of these mixtures was about 1 .

An absorption spectrum of a typical filter is shown in figure 15. The peaks at 302 and $512 \mathrm{~nm}$ are due to absorption by $\mathrm{NO}_{3}^{-}$and $\mathrm{Co}\left(\mathrm{H}_{2} \mathrm{O}\right)_{6}^{+2}$, respectively. The peak at $395 \mathrm{~nm}$ and the plateau at $650-700 \mathrm{~nm}$ are due to $\mathrm{Ni}\left(\mathrm{H}_{2} \mathrm{O}\right)_{6}^{+2}$.

The filters are supplied in $10 \mathrm{ml}$ ampoules which have been prescored for easy opening. An SRM unit consists of three sets of filters, each set containing a "Blank" ( $0.1 \mathrm{~N}$ perchloric acid) and three absorbance levels of the filter. Each set is packaged in an individual tray for added convenience.

The filters were calibrated by randomly selecting ampoules from each lot. The certified absorbances are as follows:

TABLE 13. Certification of NBS SRM 931

Net absorbance ${ }^{\text {a }}$

\begin{tabular}{c|c|c|c|c}
\hline \multirow{2}{*}{ Filter } & \multicolumn{3}{|c}{ Wavelength and (Bandpass), nm } \\
\cline { 2 - 5 } & $302(1.0)$ & $395(1.7)$ & $512(2.0)$ & $678(6.5)$ \\
\hline “A"- 'Blank' & $0.307 \pm 0.003$ & $0.304 \pm 0.003$ & $0.303 \pm 0.003$ & $0.115 \pm 0.002$ \\
“B"- 'Blank' & $0.608 \pm 0.005$ & $0.605 \pm 0.005$ & $0.606 \pm 0.005$ & $0.229 \pm 0.003$ \\
"C"- 'Blank' & $0.906 \pm 0.007$ & $0.907 \pm 0.007$ & $0.911 \pm 0.007$ & $0.345 \pm 0.003$ \\
\hline
\end{tabular}

a Net absorbances "A"- 'Blank,' "B" - 'Blank,' and "C" - 'Blank' were determined using 10.00 $\mathrm{mm}$ cuvets at $25.0^{\circ} \mathrm{C}$.

The uncertainties are given at the 95 percent confidence level and include a possible systematic error of \pm 0.5 percent.

Absorbances are certified at $25.0{ }^{\circ} \mathrm{C}$. Absorbances at other temperatures in the range 17 to $37^{\circ} \mathrm{C}$ may be calculated using the formula:

$$
A_{t}=A_{25}\left[1+C_{A}(t-25)\right]
$$

where: $A_{t}=$ Absorbance at temperature $\mathrm{t}\left({ }^{\circ} \mathrm{C}\right)$

$A_{25}=$ Absorbance certified at $25.0^{\circ} \mathrm{C}$

$C_{A}=$ Fractional change in absorbance per ${ }^{\circ} \mathrm{C}$

The values of $C_{A}$ at the four wavelengths are given below.

$\begin{array}{cc}\lambda, \mathrm{nm} & C_{A} \\ & \\ 302 & -0.0014 \\ 395 & +0.0014 \\ 512 & +0.0018 \\ 678 & +0.0014\end{array}$

The absorbances of these filters will also depend on the spectral bandpass used. To insure that the measured absorbances do not differ by more than \pm 0.1 percent from the true values, the effective spectral bandpass should not exceed $1.5,2.0,3.3$, and $8.5 \mathrm{~nm}$ at $302,395,512$, and $678 \mathrm{~nm}$, respectively.

\section{Conclusion}

The availability of well characterized materials from which the analyst prepares his own solutions is preferable to the issuance of ampouled liquids. Although the former are not as convenient to use, they offer potentially greater accuracy because of their better stability.

The potassium dichromate and potassium hydrogen phthalate used in this study are issued by NBS as primary oxidimetric and acidimetric standards (SRM $136 \mathrm{c}$ and $84 \mathrm{~g}$, respectively). The potassium nitrate is presently issued as a thermal analysis standard (SRM 756). A product of comparable purity may be 
obtained by repeated recrystallization of reagent-grade material from distilled water. The cobalt and nickel solutions are best prepared from the high purity metals which are commercially available.

To certify absorptivities for these materials, one must resolve the question as to how well these systems obey Beer's law. For acidic potassium dichromate, the increased dimerization of $\mathrm{HCrO}_{4}^{-}$to $\mathrm{Cr}_{2} \mathrm{O}_{\overline{7}}$ with increasing chromium concentration primarily accounts for the relatively large deviations observed. With potassium nitrate, one can only speculate that ionic interactions are enhanced at the higher concentrations. In neither instance are these deviations suffciently large to limit the usefulness of these materials as liquid absorbance standards. Such deviations do require that the absorptivity data be used with proper precautions.

Additional studies are needed to explain the 0.20.3 percent deviations from Beer's law obtained for the various concentrations of alkaline chromate, potassium hydrogen phthalate, cobalt perchlorate and sulfate, and nickel perchlorate and sulfate. Although internal multiple reflection effects appear to be of the proper magnitude to account for these differences, initial attempts to measure such effects with magnesium fluoride-coated cuvets have not been successful. While extremely durable, magnesium fluoride reduces reflections by about 50 percent and more efficient coatings will probably be needed to resolve this problem. If internal reflections are responsible for the observed deviations, the absorptivity data given should not be corrected when using liquid absorbance standards for checking the accuracy of the photometric scale since these reflections are included in every measurement. However, in the determination of molar absorptivity, which is considered a fundamental property of the material, appropriate corrections should be applied. Until this question can be resolved, it is recommended that these materials be used at concentrations which yield an absorbance of at least 0.5 when measured in a 10 $\mathrm{mm}$ cuvet. With this restriction, it is believed that the uncertainty of the absorptivity data does not exceed \pm 0.5 percent at the 95 percent confidence level.

The authors wish to express their appreciation to Radu Mavrodineanu for providing the calibrated Schott filters and to David S. Bright for performing the computer calculations on the $\mathrm{HCrO}_{4}^{-} / \mathrm{Cr}_{2} \mathrm{O}_{\overline{7}}$ equilibrium.

\section{References}

[1] Gibson, K. S., Nat. Bur. Stand. Circular 484 (1949).

[2] Harrison, G. R., M.I.T. Wavelength Tables (John Wiley \& Sons, Inc., New York, N.Y., 1969).

[3] Meehan, E. J., 'Treatise on Analytical Chemistry', Kolthoff, I. M., and Elving, P. J., Editors, Part 1, Volume 5, Chapter 54 (John Wiley \& Sons, Inc., New York, N.Y., 1964).

[4] Hardy, A. C., and Young, F. M., J. Opt. Soc. Am. 39, 365 (1949).

[5] Eberhardt, W. H., J. Opt. Soc. Am. 40, 172 (1950).

[6] Broderson, S., J. Opt. Soc. Am. 44, 22 (1954).

[7] Hogness, T. R., Zscheile, F. P., and Sidwell, A. E., J. Phys. Chem. 41, 379 (1937).

[8] Perry, J. W., Photoelectric Spectrometry Group Bull. 3, 40 (1950).

[9] Slavin, W., Anal. Chem. 35,561 (1963).

[10] Poulson, R. E., Appl. Opt. 3,99(1964).

[11] Goldring, L. S., Hawes, R. C., Hare, G. H., Beckman, A. O., and Stickney, M. E., Anal. Chem. 25, 869 (1953).

[12] British Standard 3875, British Standards Institution (1965).

[13] Mavrodineanu, R., Nat. Bur. Stand. (U.S.), Tech. Note 584, 178 pages (1971), O. Menis and J. I. Schultz, Eds.

[14] Vandenbelt, J. M., Forsyth, J., and Garrett, A., Anal. Chem. 17, 235 (1945).

[15] Haupt, G. W., J. Opt. Soc. Am. 42, 441 (1952).

[16] Haupt, G. W., J. Res. Nat. Bur. Stand. 48, 414 (1952).

[17] Vandenbelt, J. M., and Spurlock, C. H., J. Opt. Soc. Am. 45, 967 (1955).

[18] Gridgeman, N. T., Photoelectric Spectrometry Group Bull. 4, 67 (1951).

[19] Ketelaar, J. A. A., Fahrenfort, J., Haas, C., Brinkman, G. A., Photoelectric Spectrometry Group Bull. 8, 176 (1955).

[20] Va.udenbelt, J. M., J. Opt. Soc. Am. 50,24 (1960).

[21] Ringbom, A., Complexation in Analytical Chemistry, (John Wiley \& Sons, Inc., New York, N.Y., 1963), p. 294.

[22] Neuss, J. D., and Rieman, W., J. Am. Chem. Soc. 56, 2238 (1934).

[23] Howard, J. R., Nair, V. S. K., and Nancollas, G. H., Trans. Faraday Soc. 54, 1034 (1958).

[24] Tong, J., and King, E. L., J. Am. Chem. Soc. 75, 6180 (1953).

[25] Davies, W. G., and Prue, J. E., Trans. Faraday Soc. 5 1, 1045 (1955).

[26] Haight, G. P., Richardson, D. C., and Coburn, N. H., J. Inorg. Chem. 3, 1777 (1964).

[27] Johnson, E. A., Photoelectric Spectrometry Group Bull. 17, 505 (1967).

[28] Edisbury, J. R., Photoelectric Spectrometry Group Bull. 1, 10 (1949).

[29] Edisbury, J. R., Photoelectric Spectrometry Group Bull. 16, 441 (1965)

[30] Malitson, I., private communication.

[31] Rains, T. C., private communication.

[32] Ewing, G. W., and Parsons, T., Anal. Chem. 20, 423 (1948).

[33] Swift, T. J., and Connick, R. E., J. Chem. Phys. 37, 307 (1962).

[34] Thomson, L. C., Trans. Faraday Soc. 42, 663 (1946).

[35] Hall, H. T., and Eyring, H., J. Am. Chem. Soc. 72, 782 (1950).

[36] Burke, R. W., and Deardorff, E. R., Nat. Bur. Stand. (U.S.), Tech. Note 544, 153 pages (1970), O. Menis and J. I. Schultz, Eds.

[37] Ciba Chemical and Dye Company, Fair Lawn, New Jersey.

[38] Industrial Chemicals Division, Allied Chemical Corporation, Buffalo, New York. 